\title{
Perceptions about caesarean section among women and health care providers: a qualitative study in a rural maternity hospital in Karnataka, India
}

\author{
Teny Attokaran, Merlyn Joseph*, Ramya B., Caroline Pretista D'souza, Soumya, \\ Maria Mary Mathew, Rathna Kumari, Avita Rose Johnson
}

Department of Community Health, St John's Medical College, Bangalore, Karnataka, India

Received: 22 November 2019

Accepted: 30 December 2019

*Correspondence:

Dr. Merlyn Joseph,

E-mail: dr.merlyn.joseph@gmail.com

Copyright: () the author(s), publisher and licensee Medip Academy. This is an open-access article distributed under the terms of the Creative Commons Attribution Non-Commercial License, which permits unrestricted non-commercial use, distribution, and reproduction in any medium, provided the original work is properly cited.

\begin{abstract}
Background: Caesarean section is life-saving, but rising rates are a cause for concern. Perceptions surrounding caesarean delivery may play a significant role in the shared-decision making process. Objective of this study was to explore the perceptions of caesarean section among antenatal, postnatal women and healthcare providers in a rural maternity hospital in Ramanagara district, Karnataka.

Methods: Qualitative research methodology was adopted to explore perceptions regarding preferred birthing mode, caesarean and its perceived complications. Focus group discussions and in-depth interviews were conducted with antenatal and postnatal women, their caregivers and health care providers. Inductive coding approach and thematic framework analysis was done.

Results: Five major themes emerged regarding perceptions of caesarean section among women in a rural area of Karnataka: understanding, fears, decision making, after-care and prevention. Women had a strong preference for normal vaginal birth, but willing to accept doctor's decision for caesarean as they believed that it would protect the life of unborn child. Women perceived that caesarean was profitable to the hospital. Common mentioned side effects following caesarean were backache and pain at the surgical site.

Conclusions: The understanding regarding caesarean section was adequate. Women had fears linked to caesarean such as pain, inability to work, weight gain, prolonged recovery and caesarean deliveries in subsequent pregnancies. Husbands and other family members as well as the doctors were the important decision makers, while the women themselves had little say in the matter. Obstetricians need to focus on alleviating concerns among pregnant women and their family members regarding caesarean section.
\end{abstract}

Keywords: Attitude, Caesarean section, Decision-making, Perception, Qualitative study

\section{INTRODUCTION}

Caesarean section is an alternative for women when a vaginal delivery is not possible. ${ }^{1}$ The indications for a caesarean section could be maternal or foetal. It is a relatively safe surgical procedure, though there may be some associated complications. ${ }^{2}$ Caesarean section is a life-saving surgical intervention for women and their new-borns however its recent over-utilization is a global public health concern. ${ }^{3}$ The practice of modern obstetrics has seen a persistent increase in the caesarean section rate, which could pose a public health problem since caesarean section increases the health risk for mothers and babies as well as increases the cost of health care compared to normal deliveries. It is not easy to determine the actual cause for the increasing rates of caesarean 
sections. Medical, institutional, legal, psychological and socio-demographic factors play an important role. 2 Although infant mortality has reduced during the same period, there is little evidence that more frequent caesarean births are the cause. Chile and Brazil (both developing countries) have the maximum caesarean section rates in the world ( $40 \%$ and $37 \%$, respectively). ${ }^{4}$ The overall rate of caesarean section delivery in 2015-16 is around $17.2 \%$ in India, increased from $8.5 \%$ in 2005-6. However, the caesarean section rate is lower in rural areas $(12.9 \%)^{5}$

The perceptions and personal experience of health providers and pregnant women often influence the decision regarding the mode of delivery. ${ }^{6,7}$ Although caesarean section is a consensus idea in developed countries; in developing countries, social and cultural paradigms for women influence them to reject caesarean section due to certain beliefs. ${ }^{8}$ There is a paucity of relevant literature in the South Asian context, and therefore this study was conducted with the aim of exploring the perception of caesarean section among women and health care providers attending a rural maternity hospital in the South of Karnataka.

\section{METHODS}

This was a qualitative study conducted at a rural maternity hospital located in a village in Ramnagara district, in the south of Karnataka state, around $70 \mathrm{kms}$ from Bangalore city, during the months of September and October 2018. Ethical approval for this study was obtained from the Institution Ethics Committee of St. John's National Academy of Health Sciences, Bangalore (Study no.307/2018). Permission to conduct the study was also obtained from the medical officer in-charge of the rural maternity hospital.

Inclusion criteria antenatal, postnatal and non-pregnant women in the reproductive age group and their female care givers who were admitted in the rural maternity hospital. Exclusion criteria- those who were seriously ill.

Data was collected by means of focus group discussions (FGDs) and in-depth interviews (IDIs), using preprepared topic guides. Participant selection was purposive, in order to include the perspectives of different cadre of health care providers and women across different ages within the reproductive age group and across different reproductive stages (antenatal, postnatal, non-pregnant). Written informed consent was obtained from those willing to participate in the study and a subject information sheet was provided. Permission for audio recording of discussions and interviews was also obtained.

Using an iterative approach, five FGDs were conducted, till data saturation was achieved; two FGDs with antenatal mothers, two FGDs with postnatal mothers and one FGD with non-pregnant women (caregivers of postnatal mothers). Six IDIs were conducted; two IDIs with postnatal mothers who had undergone caesarean section, one IDI with a female caregiver of a postnatal mother who had undergone caesarean section, two IDIs with staff nurses, and one IDI with the consultant obstetrician at the hospital. Except for the IDI with the obstetrician and staff nurses, all the IDIs and FGDs were conducted in the local language (Kannada). Sociograms were plotted during the FGDs to ensure equal participation of the women. There were 8-10 women included in each FGD. The duration of the each FGD or IDI was 40-60 mins. A health education session was conducted for all participants of the FGDs regarding caesarean section, its indication, benefits and adverse effects.

\section{Statistical analysis}

Audiotapes were transcribed ad verbatim from Kannada to English, and then entered into a word document. The transcripts were manually coded, using codes developed inductively, Thematic framework analysis was used to identify the various themes exploring the perceptions of caesarean section among the study population.

\section{RESULTS}

The average age of the pregnant women, post-natal mothers and care givers who participated in the FGDs was 23, 22 and 46 years respectively. The education status of antenatal and postnatal mothers ranged from middle school to master's degree and that of care givers was illiterate to primary school. The antenatal women in the FGD were a mix of primi and multigravida, one of whom had a caesarean section. The postnatal mothers comprised of primipara and multipara, four of whom had undergone caesarean section. All the care givers had normal vaginal delivery and were multiparous.

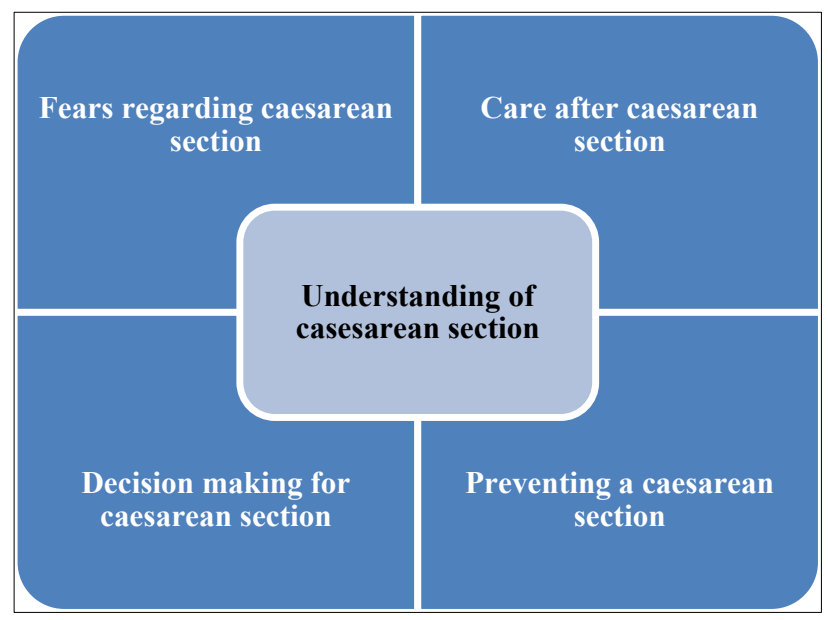

Figure 1: Thematic framework prepared after analysis using inductive codes.

Five major themes emerged regarding perceptions about caesarean section among the participants: understanding 
of caesarean section, fears regarding caesarean section, decision making for caesarean section, care after caesarean section, preventing a caesarean section. (Figure 1) Under the theme of understanding about caesarean section, the subthemes included were 'what is it called?', 'who performs?', 'where is it performed?', 'why is it performed?', procedure and anaesthesia, cost, subsequent births, source of information, preference were formed.

\section{Understanding of caesarean section}

The pregnant women, post-natal women and the care givers in the study, called it 'caesarean'. Some of them used the term 'operation'. There was no other term for caesarean used colloquially, nor in the local language. All of them knew that, the doctors perform caesarean section. Some of them even specified that these doctors were called 'gynaecologists. "Big doctor and nurse they are not aware of the anaesthetist." (IDI-nurse). Most of them thought that caesarean section can be done in all hospitals, some felt that it can be done in private hospitals only. The reason is that women feel that though the government hospitals are equipped, doctors are not available, whereas in private hospitals, doctors are present all the time. Most of the women knew that caesarean section is done in an operation theatre, but some believed that it is done in the labour room. Most of them felt that caesarean section was performed for protecting the health of the baby.

Primary reasons for caesarean section stated by them were: health of the unborn child being the most common, others include baby not in proper position, big baby, multiple gestation, premature rupture of membranes, cord around the neck. A few were aware of maternal indications such as uncontrolled hypertension, short stature of mother. "Tension, lifestyle, food, climate when it is hot, there is more fever and headache. All these can be reasons for caesarean." (FGD-Antenatal women). The women were of the opinion that those who were not tolerating labour pains could opt for caesarean section. Sometimes it could simply be a choice that pregnant women made in order to avoid normal delivery. Some felt that women who wanted to undergo tubectomy, would prefer a caesarean section, so that both could be done as one procedure.

All the women knew that caesarean section costs significantly more than normal vaginal delivery. Reasons cited for the higher cost were the use of instruments, machines, medicines, and longer hospital stay. Some women felt that caesarean section means a profit for the hospital, and therefore the doctors may decide to perform caesarean for profit. "It is expensive and they (hospital) will get good income." (FGD- Post-natal women). "It will be a profit for the hospital when they give a bill of 2 to 3 lakhs." (FGD- care giver).

Most of the women had a good understanding about the actual procedure of caesarean section, where an incision is made on the abdomen and baby is taken out. They also mentioned that an injection is given in the spine prior to caesarean section. Anaesthesia in colloquial terms was described as "Pragne thappodu (loss of sensation)." (FGD-Antenatal women).

Many women agreed with the dictum "once a caesarean, always a caesarean." Most felt that subsequent births after the first caesarean section would invariably be a caesarean section. Few were aware that normal vaginal delivery is also possible. Most women were of the opinion that there should be birth spacing of three to five years between pregnancies after a caesarean delivery. Reasons elicited were uterus will be weak, stitches need to heal, to increase chances of subsequent normal delivery and financial problems due to costs of caesarean.

Most women learnt about caesarean section from their relatives/neighbours who had undergone caesarean section. Only one person said she got information from television. When asked regarding their preferred mode of childbirth, most of the women preferred normal delivery, very few preferred caesarean sections, citing the reason that during normal delivery they have to strain to deliver the baby, but with caesarean section the doctor gives anaesthesia, and the baby is taken out without pain.

\section{Fears regarding caesarean section}

Two of the most mentioned side effects after caesarean section were backache and pain at the surgical site. Back pain was considered as a side effect of the injection given during anaesthesia. Majority of the women felt that they would be unable to perform household activities post caesarean section. They were also scared that after caesarean section they would not be able to take care of their baby like mothers who underwent normal delivery because of pain at the surgical site. Some feared that after caesarean section, they might not be able to lead a normal life. "After normal delivery within two to three months they would have completely recovered. But caesarean section even after two to three years they will feel tired and weak. You can't bend too much. It is not possible to bend and do work (after caesarean)." (FGD- Antenatal women).

Weight gain was also another fear after caesarean section. "you will put on weight authors don't prefer caesarean" (FGD- Antenatal women). "They ask questions whether they will put on weight, and will the scar be visible or does it increase in size." (IDI- Nurse). "After that caesarean delivery water will not be cleared that's why they get pain during first periods after caesarean." (FGDantenatal women).

Though most women felt that caesarean section was a safe procedure, a few said they heard about deaths postcaesarean section. Another fear was the high costs of caesarean section, as compared to a normal delivery. 


\section{Decision making for caesarean section}

The women felt that the parents of the antenatal woman play a key role in decision making, as they are the ones taking care of her. "Mother, father. Only if there is permission from family members, they will do caesarean or else they won't." (FGD- Antenatal women). Some insisted that the decision maker in the family is the husband. "Husband has to take care of the woman after caesarean, so if there is any problem, he only has to take care of it. So that's why husband's decision is important." (FGD-care giver). Very few felt that the women themselves have the freedom to decide. Some women succumb to extreme levels of family pressure to have a normal delivery. "One particular lady, she wanted to have a normal delivery, she was bearing down bearing down, it didn't happen, authors took her for caesarean, she came back and later continued to bear down. family people were going on telling her that you should have normal delivery. So that had really recorded in her brain." (IDIObstetrician).

\section{Care after caesarean section}

Most women felt that after caesarean, a minimum of seven to nine days of hospital stay and a minimum of six to nine months of rest was required. "authors keep them for at least a week because of hygienic condition, they don't take care at home and because of their superstitious beliefs, they won't get to eat properly. So that will all come in the way of healing the wound." (IDIObstetrician). Even the families preferred that the antenatal women who undergo caesarean should stay longer in the hospital. "At home, all may not be having toilets, they may have to squat, they have to climb the stairs, so they prefer to stay in the hospital" (IDIObstetrician). Most women were aware that full body bath plus wound care with soap and water is needed daily after caesarean section.

Though most women responded that there was no difference in the diet based on the mode of delivery, some had differing opinions. "With caesarean they will get low blood pressure and that's why they need normal food, those who have undergone normal delivery, they need less quantity and little bland food." "After caesarean if they eat too much the abdomen will be tight, so they shouldn't eat too much. If they eat solid food there will be difficulty in passing stools and the stitches will come out." (FGD-Caregivers).

\section{Preventing a caesarean section}

All the women believed that eating nutritious food will reduce the chances of caesarean delivery. The older women in the family advised them to avoid caesarean by not eating cold and oily foods. They were advised to consume more ragi, vegetables, fruits, spinach and drink a lot of hot water. "Sometimes they drink some kashaya mostly with jeera. Authors had one lady for whom authors had advised caesarean section and so the family brought kashaya with jeera." (IDI- Nurse). Most women felt that doing more physical activity like washing vessels, washing clothes, cooking and other household chores would reduce their chances of having a caesarean delivery. They were advised by the older women in the family to do more work at home to facilitate a normal delivery. "Do more work, you will get more exercise, and so, gain physical strength. People in the old days, in previous years used to work be healthy. Body used to remain "free". Doctor also tells us to do yoga, exercise, so that body becomes free." (FGD - antenatal woman). When you sit, you shouldn't sit on the floor with both legs towards one side, the baby will rotate. If you want a normal delivery, sit cross-legged." (FGD - antenatal women).

\section{DISCUSSION}

This study explored the perception of caesarean section among women in the socio-cultural context of a rural area in South India. Rural women in this study seem familiar with the term 'caesarean' and the concept of who performs a caesarean and how it is performed, reflecting an adequate awareness level, similar to that found in other studies overseas. In a study conducted among pregnant women in a semi-urban community in Northwest Nigeria, $93.8 \%$ of the respondents were aware of caesarean section and those who were not regular with their routine antenatal check-ups had poor knowledge of caesarean section, indicating the need to educate women on the different modes of delivery during the antenatal period so that caesarean section will not be entirely strange to them when decided upon during the period of labour. ${ }^{9}$ This may shorten the time interval between decision making and consent.

The present study elicited many fears that seem to make the women resistant to the idea of undergoing a caesarean section: high costs, longer duration of stay in the hospital, fear of side-effects like backache and pain at the operation site, fear of not being able to do housework and look after the family for a prolonged time. These concerns should be addressed by the treating obstetrician when advising a pregnant woman to undergo caesarean section. In the study conducted at Abakaliki, Nigeria among women attending routine antenatal clinic, fear of death was the major reason women refused caesarean section. ${ }^{1}$ This was not seen in this study, as the women in this study had better access to information and education, as compared to their Nigerian counterparts.

Due to many different fears, most of the women said they preferred normal delivery. Very few preferred caesarean sections. This was similarly found in a quantitative study in southwest Nigeria, where majority $(94.2 \%)$ preferred vaginal delivery, as well as in a rural community in Bangladesh, where women expressed a strong preference for normal vaginal birth. ${ }^{3,10}$ Women often perceive the failure to have a normal delivery as a reproductive 
failure, a failure as a woman or as a sign of weakness. This is in part due to the fact that typical rates of caesarean section in rural India still hovers around the $10 \%$ mark, and what is uncommon, often ends up being stigmatized.

Negative connotations to the word "caesarean" are partly due to the perceived prolonged recovery period. Women need to be counselled that modern medicine has resulted in early ambulation, and that bed-rest is no longer part and parcel of a post-caesarean scenario. While all women should avoid heavy work in the postnatal period, there is no reason preventing women from doing simple household chores, irrespective of their mode of delivery. Women should be advised that clinging to the notion of a normal delivery when a caesarean section is indicated, would result in delayed consent, loss of precious time and adverse maternal and foetal outcomes.

In the present study, the husband and parents seem to play a key role in decision making, indicating the lack of autonomy among rural women. This was echoed in other studies: Abakaliki, Nigeria where $66.5 \%$ believe their husbands should be the one to give consent for caesarean section. This is not surprising as in most rural settings major decisions are often left to the men who are considered the head of the family. The flip side of this cultural paradigm is that there may be delay in decision making, waiting for the husband to arrive for consent, or due to the husband's reluctance to agree for a caesarean section.

In general, women in this rural community, while preferring normal deliveries, were willing to accept the doctor's decision for a caesarean, if deemed necessary. Two of the most feared consequences post caesarean section in the study were backache and pain at the surgical site. These concerns may be addressed by the obstetrician, stressing on effective pain management.

Limitations and methodological considerations of this study were that findings may not represent women's and obstetricians' views from other areas in India. While the objective of the study was not to produce nationally representative results, authors did provide adequate socio-cultural contextual description allowing readers to determine whether these findings would be relevant in other rural areas of India.

\section{CONCLUSION}

Five major themes emerged regarding perceptions of caesarean section among women in a rural area of Karnataka: understanding, fears, decision making, aftercare and prevention. From the study it was found that the understanding regarding caesarean section was adequate. Women perceived that caesarean section was profitable to the hospital while the patient incurs high expenses. Women preferred normal vaginal delivery, likely due to fears linked to caesarean section such as pain, inability to work, weight gain, prolonged recovery and caesarean deliveries in subsequent pregnancies. Husbands and other family members as well as the doctors were the important decision makers, while the women themselves had little say in the matter. To enable a better-informed consent process prior to caesarean, obstetricians need to focus on alleviating these concerns. Relevant information during the antenatal period about modes of delivery, their indications, advantages and adverse consequences will enable women and their families to make an informed decision if caesarean section is advised.

\section{ACKNOWLEDGMENTS}

Authors would like to thank all the staff and patients in the rural maternity hospital in Ramanagara district, Karnataka. Authors also like to extend their my gratitude to the entire Department of Community Health St. Johns Medical College, Bangalore, Karnataka, India.

Funding: No funding sources

Conflict of interest: None declared

Ethical approval: The study was approved by the Institutional Ethics Committee

\section{REFERENCES}

1. Ezeonu PO, Ekwedigwe KC, Isikhuemen ME, Eliboh MO, Onoh RC, Lawani LO, et al. Perception of caesarean section among pregnant women in a rural missionary hospital. Adv Reprod Sci. 2017;5(3):33-8.

2. Ajeet S, Jaydeep N, Nandkishore $K$, Nisha R. Women's knowledge, perceptions, and potential demand towards caesarean section. Natl J Community Med. 2011;2(2):244-8.

3. Begum T, Ellis C, Sarker M, Rostoker JF, Rahman A, Anwar I, et al. A qualitative study to explore the attitudes of women and obstetricians towards caesarean delivery in rural Bangladesh. BMC Preg Childbirth. 2018;18(1):368.

4. Sreevidya S, Sathiyasekaran BWC. High caesarean rates in Madras (India): a population-based cross sectional study. BJOG An Int J Obstet Gynaecol. 2003;110(2):106-11.

5. India-Key Indicators India-Key Indicators International institute for population sciences. Available http://www rchiips org/nfhshttp://www iipsindia org. Accessed on 3 February 2019.

6. Gunnervik C, Sydsjö G, Sydsjö A, Ekholm Selling $\mathrm{K}$, Josefsson A. Attitudes towards cesarean section in a nationwide sample of obstetricians and gynecologists. Acta Obstet Gynecol Scandinavica. 2008;87(4):438-44.

7. Khatony A, Soroush A, Andayeshgar B, Saedpanah $\mathrm{N}$, Abdi A. Attitude of primiparous women towards their preference for delivery method: a qualitative content analysis. Arch Public Heal. 2019;77(1):38. 
8. Qazi Q. Pregnant women view regarding cesarean section in Northwest Pakistan. Trop Med Surg. 2013;1(1):1-4.

9. Ashimi A, Amole T, Aliyu L. Knowledge and attitude of pregnant women to caesarean section in a semi-urban community in northwest Nigeria. J West African Coll Surg. 2013;3(2):46-61.

10. Owonikoko KM, Akinola S, Adeniji OA, Bankole AO. WomenÂ's perception and experience of caesarean delivery in Ogbomoso, Southwest Nigeria. J Pregnancy Child Heal. 2015;2(3):1-6.
Cite this article as: Attokaran T, Joseph M, Ramya B, D'souza CP, Soumya, Mathew MM, et al.

Perceptions about caesarean section among women and health care providers: a qualitative study in a rural maternity hospital in Karnataka, India. Int J Reprod Contracept Obstet Gynecol 2020;9:646-51. 